\title{
AMPA- and NMDA-Associated Postsynaptic Protein Expression in the Human Dorsolateral Prefrontal Cortex
}

\author{
MONICA BENEYTO AND JAMES H. MEADOR-WOODRUFF \\ Mental Health Research Institute and Department of Psychiatry, \\ University of Michigan, Ann Arbor, Michigan 48109, USA
}

\section{INTRODUCTION}

Pharmacological and anatomical data suggest that abnormal glutamate neurotransmission may be associated with the pathophysiology of schizophrenia and mood disorders. Glutamate is the primary excitatory neurotransmitter in the central nervous system. It regulates numerous cellular signaling cascades and controls the excitability of central synapses both pre- and postsynaptically. Region-specific localization, cell surface expression, and activity-dependent regulation of neurotransmitter receptors in neurons are essential for their function. In addition, there is a complex network of postsynaptic density proteins (PSD) that act via specific protein-protein interactions to serve as scaffold/adaptor proteins targeting, anchoring, and spatially organizing synaptic proteins in the cell membrane. Proteins that are specific for individual subunits that form the ionotropic glutamate receptors have been identified. Recently, we have shown that there are abnormalities in NMDA receptor expression as well as the expression of some of these PSD proteins in the thalamus in schizophrenia. ${ }^{1}$ The distribution and levels of expression of these molecules in the human cerebral cortex is largely unknown, however, and characterization of the cortical expression of these molecules in human brain was the goal of this study.

\section{METHODS}

We used in situ hybridization to determine the laminar distribution and transcript expression levels of NMDA (PSD95, NF-L)- and AMPA (NSF, PICK-1)-associated $\mathrm{PSD}$ proteins in the dorsolateral prefrontal cortex. We used specific $\left[{ }^{35} \mathrm{~S}\right]$-labeled riboprobes designed for human PSD95, NF-L, NSF, and PICK-1 as we have previously described in detail. ${ }^{2-4}$ Images were acquired from digitized X-ray films with a CCD imaging system.

\footnotetext{
Address for correspondence: Monica Beneyto, Ph.D., Mental Health Research Institute and Department of Psychiatry, University of Michigan, 205 Zina Pitcher Place, Ann Arbor, MI 48109. Voice: 734-936-2056; fax: 734-647-4130.

mbeneyto@umich.edu
}

Ann. N.Y. Acad. Sci. 1003: 352-355 (2003). (C) 2003 New York Academy of Sciences. doi: 10.1196/annals.1300.024 

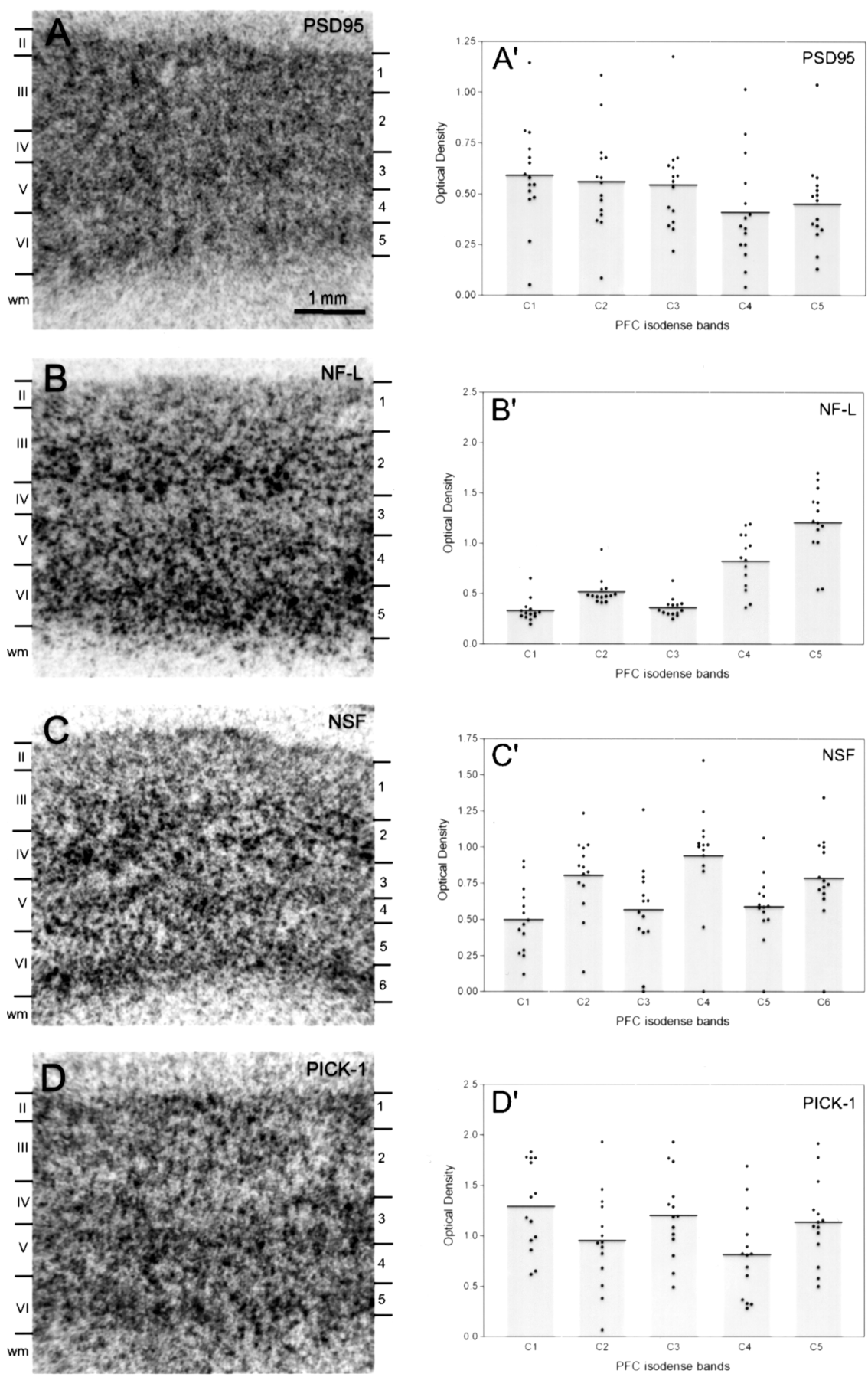

FIGURE 1. See following page for legend. 


\section{RESULTS AND COMMENT}

We found specific laminar patterns of expression for each of the PSD proteins studied. Transcripts encoding PSD95, which binds to both NMDA (NR2) and kainate (GluR6/KA2) subunits, were expressed at similar levels in all laminae, with slight enrichment in layers II, IV, and VI. NF-L, a protein exclusively related to NMDA receptors (binding to exon 21 of NR1) had a different pattern of laminar expression. NF-L mRNA was highly expressed in two thin bands corresponding to layers III and the superficial aspect of layer V, as well as in a wider band associated with layer VI. A granular appearing hybridization signal was distinct from the more homogeneous pattern seen for PSD95.

For the AMPA-associated PSD proteins, transcripts encoding NSF (which binds GluR1-4) were moderately expressed in layers II, IV, and the deep aspect of layer V, and high in layers III and V-VI. PICK-1 mRNA was expressed at moderate to high levels throughout the entire cortical depth, with maximum levels of expression in layers II, IV, and VI.

Previous publications have reported changes in the expression of some of these molecules in schizophrenia, either by in situ hybridization (PSD95), ${ }^{5}$ or by microarray (NSF). ${ }^{6}$ On the other hand, NF-L and PICK-1 have thus far not been studied in schizophrenia. Previous work has been done in tissue homogenates, but has not yet focused on laminar or cellular changes. Our present study provides the normal patterns of expression in the prefrontal cortex of four of these molecules, and given the heterogeneity of expression, suggests that subsequent studies of these molecules in schizophrenia should target laminar and cellular resolution.

\section{ACKNOWLEDGMENT}

This work has been supported by Grant MH53327 from the NIMH (JMW).

\section{REFERENCES}

1. Clinton, S.M., V. Haroutunian, K.L. Davis \& J.H. Meador-Woodruff. 2002. Am. J. Psychiatry. 2003. In press.

2. Healy, D.J., V. Haroutunian, P. PowchiK, et al. 1998. AMPA receptor binding and subunit mRNA expression in prefrontal cortex and striatum of elderly schizophrenics. Neuropsychopharmacology 19: 278-286.

3. Ibrahim, H.J., A.J. HogG, D.J. Healy, et al. 2000. Ionotropic glutamate receptor binding and subunit mRNA expression in thalamic nuclei in schizophrenia. Am. J. Psychiatry 157: 1811-1823.

FIGURE 1. (A-D) Photomicrographs of film autoradiograms from adjacent sections of the dorsolateral prefrontal cortex. Laminar distribution of transcripts encoding PSD-95 (A), NF-L (B), NSF (C), and PICK-1 (D). On the left side of each panel are the boundaries of the cortical layers identified by Nissl staining and on the right isodense bands that were measured. $\left(\mathbf{A}^{\prime}-\mathbf{D}^{\prime}\right)$ Optical density values of isodense bands. Data are expressed as means as well as individual values from cortical layer I (left) to VI (right). 
4. Ibrahim, H.J., D.J. Healy, A.J. Hogg \& J.H. Meador-Woodruff. 2000. Nucleus-specific expression of ionotropic glutamate receptor subunit mRNAs and binding sites in primate thalamus. Mol Brain Res. 79: 1-17.

5. Ohnuma, T., H. Kato, H. Arai, et al. 2000. Gene expression of PSD95 in prefrontal cortex and hippocampus in schizophrenia. Neuroreport 28(11): 3133-3177.

6. Mirnics, K., F.A. Middleton, A. Marquez, et al. 2000. Molecular characterization of schizophrenia viewed by microarray analysis of gene expression in prefrontal cortex. Neuron 28: 53-67. 